\title{
Estimation of Performance Indices for the Planning of Sustainable Transportation Systems
}

\author{
Alexander Paz, ${ }^{1}$ Pankaj Maheshwari, ${ }^{1}$ Pushkin Kachroo, ${ }^{2,3}$ and Sajjad Ahmad \\ ${ }^{1}$ Department of Civil and Environmental Engineering, University of Nevada, Las Vegas, NV 89154-4015, USA \\ ${ }^{2}$ Transportation Research Center, Harry Reid Center for Environmental Studies, University of Nevada, Las Vegas, \\ NV 89154-4007, USA \\ ${ }^{3}$ Department of Electrical and Computer Engineering, University of Nevada, Las Vegas, NV 89154-4026, USA
}

Correspondence should be addressed to Alexander Paz; apaz@unlv.edu

Received 15 September 2012; Revised 2 January 2013; Accepted 16 January 2013

Academic Editor: Ching-Hung Lee

Copyright (C) 2013 Alexander Paz et al. This is an open access article distributed under the Creative Commons Attribution License, which permits unrestricted use, distribution, and reproduction in any medium, provided the original work is properly cited.

In the context of sustainable transportation systems, previous studies have either focused only on the transportation system or have not used a methodology that enables the treatment of incomplete, vague, and qualitative information associated with the available data. This study proposes a system of systems (SOS) and a fuzzy logic modeling approach. The SOS includes the Transportation, Activity, and Environment systems. The fuzzy logic modeling approach enables the treatment of the vagueness associated with some of the relevant data. Performance Indices (PIs) are computed for each system using a number of performance measures. The PIs illustrate the aggregated performance of each system as well as the interactions among them. The proposed methodology also enables the estimation of a Composite Sustainability Index to summarize the aggregated performance of the overall SOS. Existing data was used to analyze sustainability in the entire United States. The results showed that the Transportation and Activity systems follow a positive trend, with similar periods of growth and contractions; in contrast, the environmental system follows a reverse pattern. The results are intuitive and are associated with a series of historic events, such as depressions in the economy as well as policy changes and regulations.

\section{Introduction}

1.1. Background. With the rapid increase in economic development throughout the world, there is stress on the resources used to support global economy, including petroleum, coal, silver, and water. Currently, the world is consuming energy at an unprecedented rate never seen before. Based on data from 2005 , about 30.6 billion barrels of petroleum are used annually worldwide [1]. The estimates indicate that the availability of total world reserves is in the vicinity of 1.3 trillion barrels and will be depleted by 2047 [2]. The finite nature of such nonrenewable natural resources as petroleum and coal puts pressure on the environmental system and ultimately reduces the availability of resources for future generations. Hence, it is critical to develop planning and operational strategies that seek to achieve a sustainable use of existing natural resources.

The development of a sustainable system and its corresponding planning strategies requires an adequate definition of sustainability as well as mechanisms to quantify, qualify, and assess sustainability. The quantification of sustainability poses considerable challenges, ranging from data availability to adequate methods to process information. Numerous studies have established different measures to quantify sustainability [3]. According to Bell and Morse [4], sustainability primarily is measured by means of three components: (i) time scale, (ii) spatial scale, and (iii) system quality. The time and spatial scale corresponds to the analysis period and the geographical region of interest, respectively. On the other hand, system quality corresponds to the quantification of the overall system performance or state. In order to quantify system quality, Sustainability Indicators (SIs) have been developed in a diverse range of fields, including biology and the life sciences, hydrology, and transportation. Harger and Meyer [5] argued that SIs should be simple, diverse, sensitive, timely, quantifiable, and accessible. Bossel [6] proposed a systembased approach for developing 21 SIs for environmental 
characteristics. The approach suggested that a system cannot exist independently, and several external factors can intrude on its boundaries. Some studies argue about the various dimensions associated with sustainability considerations [7, 8].

It is clear that a truly sustainable state for a system requires all the relevant interdependent subsystems/sectors and components, at levels so that the consumption of and the impact on the natural and economic resources do not deplete or destroy those resources. Hence, the assessment of a system state requires a holistic analysis in order to consider all the relevant sectors and impacts. However, existing approaches used to study the sustainability of a transportation system are not comprehensive enough to include key interactions with other systems such as the environment, the economy, and society in general. For example, the current planning of transportation systems is limited in terms of the number, accuracy, length, and approaches used to consider simultaneously important characteristics, including energy consumption, emissions, accidents, congestion, reliability, economic growth, and such social impacts as human health. That is, the existing practices only consider some effects, the estimations are approximate [9], and the analysis period is relatively short, in the order of 30 years [10]. In addition, these effects are synthetized only on the basis of approximated monetary considerations that are unlikely to capture the full extent of the effects, for instance, the financial cost of emissions or greenhouse gases $[11,12]$. For example, Zheng et al. [3] described various system indicators by primarily considering economic aspects. Although the study provided valuable insights about the quantification of the economic domain of transportation sustainability, it is primarily focused on the transportation sector.

Among several studies that focused on different sectors, impacts, and aspects of sustainability, the following key characteristics have emerged as fundamental for a sustainable system:

(i) continuity through time $[13,14]$;

(ii) development of the needs of current generations without compromising the needs of future generations [15];

(iii) utilization of resources without compromising their health and productivity [16];

(iv) development that improves quality of life [17]; and

(v) assimilation of economic, ecological, social, and biophysical components of resource ecosystems [18, 19].

In terms of the methodologies available to estimate SIs, numerous studies have proposed different approaches. For example, Multi-criteria Decision Making (MCDM) and Analytical Hierarchy Process (AHP) techniques have been proposed to consider multiple criteria and estimate relevant SIs [20-26]. The MCDM approach selects or ranks different predetermined alternatives and is based on making discrete decisions [23]. Traditional MCDM techniques assume that the criteria are well-defined, certain (deterministic rather than stochastic), and independent. In reality, the criteria usually involve stochasticity and interdependence. In addition, some aspects in MCDM models are subjective in nature. The weights used in MCDM always include some uncertainty. The basic idea behind the AHP is to convert subjective assessments of relative importance to a set of overall weights or scores. The scale suggested by Saaty [27] is used to compute the weights, using linear algebra. These weights are the elements in the eigenvector associated with the maximum value of the matrix. The eigenvalue-based method has been criticized by researchers on the grounds of lack of prioritization and consistency [28]. In addition, there is an issue of rank reversal possibly arising when a new criteria is added. Due to the above reasons, the theoretical foundation of a rigid scale used in the methods is also questionable [29]. There have been attempts to address some of these limitations. The computation of the weights in MCDM and AHP requires significant amounts of data and a priori or expert knowledge of the system under study. Furthermore, different regions may require different weights to capture local conditions.

Given the complexities, interdependencies, nonlinearities, vagueness, and incomplete information associated with the various factors that are generally involved when considering the sustainability of a system, some studies have adopted concepts from fuzzy set theory for the development of SIs [30-32]. Awasthi et al. [33] applied a fuzzy Technique for Order Preference by Similarity to Ideal Situation approach, to evaluate the sustainability of transportation systems using partial or incomplete information. Opricovic and Tzeng [34] used a fuzzy multi-criteria model to evaluate post-earthquake land use planning. The modeling approach was developed to deal with qualitative or incomplete information. Mendoza and Prabhu [35] applied fuzzy logic for assessing criteria and indicators for sustainable forest management. In addition, linear aggregation techniques were used to combine multiple indicators. Liu [36] tried to integrate MCDM and fuzzy logic techniques to evaluate environmental sustainability. The environmental sustainability of 146 countries was calculated, ranked, and clustered. The study was extensive in dealing with multiple variables and indicators. However, only the environment aspects of sustainability were evaluated without considering any other SIs related to the transportation or activity system. Similarly, Prato [37] discussed a fuzzy logic approach for evaluating ecosystem sustainability. Data needs as well as the lack of technical expertise were important issues in this study. Marks et al. [38] used fuzzy logic techniques to develop a theoretical framework for the evaluation of sustainable agriculture. The study argued about the advantages of fuzzy logic over conventional MCDM techniques. An important characteristic in these studies is their limited scope in terms of the system(s) considered in the analysis.

1.2. Motivation. It is clear that sustainability analysis of transportation systems requires a broad perspective including various systems, such as the economic, and the political, social, and environmental systems. This perspective enables the consideration of such relevant aspects as biodiversity, human health, quality of life, and life expectancy. Such analysis requires significant amounts of data as well as methods to develop adequate SIs. Although not all data that one may 
want to use is available, there is a vast amount of relevant information that can be obtained from such organizations as The World Bank, the United Nations, the Bureau of Transportation Statistics, and the U. S. Environmental Protection Agency.

Although fuzzy logic has been used in the context of sustainability to handle key characteristics of the relevant data, its use has not been coupled with a broad perspective considering multiple systems. To consider, explicitly, important broad effects and the characteristics of the associated data, this study proposes a system of systems (SOS) [39] and a fuzzy logic modeling approach. The SOS includes the Transportation, Activity, and Environment systems. The fuzzy logic modeling approach enables the treatment of the vagueness associated with some of the relevant data. Performance Indices (PIs) are computed for each system using a number of performance measures. The PIs illustrate the aggregated performance of each system as well as the interactions among them. The proposed methodology also enables the estimation of a Composite Sustainability Index to summarize the aggregated performance of the overall SOS.

The PIs are calculated with an emphasis on transportation systems, while explicitly considering and calculating the PIs for the other two relevant and affected systems. The PIs are calculated based on multiple performance measures with various degrees of resolution and units. These multi-resolution, multi-unit characteristics are intrinsic to the systems under consideration.

The paper is organized as follows. Section 2 describes three interdependent systems: the Transportation, Activity, and Environmental systems. Section 3 summarizes the fuzzy logic methodology used in this study. Section 4 provides information about the study region and data. Results and analysis are presented in Section 5. Some policy perspectives are illustrated in Section 6. Section 7 provides conclusions and recommendations for future work.

\section{Interdependent Systems}

In the context of sustainability, it is difficult to isolate systems or narrow the analysis to a particular region. Different systems such as Transportation have interdependencies with other systems including the economy and the environment. For example, energy resources, which are part of the environmental system, are required by both the transportation sector and the economy. Hence, any policy or strategy affecting the consumption or production of energy has effects at least on the transportation, the economy, and the environment. This research explicitly considers and defines three major interdependent systems, the transportation system, the activity system, and the environmental system.

2.1. The Transportation System. The transportation system includes all the infrastructure facilities, vehicles, operators, and control strategies used to provide transportation services to people and to move products. Thus, the overall transportation system includes all modes of transportation, including highways, transit, and fluvial and air modes.
Existing literature uses a number of measures to describe or assess transportation system performance. Lomax et al. [40] identified several measures of congestion, such as travel time, total segment delay, corridor mobility index, delay ratio, and relative delay rate. The Roadway Congestion Index uses volume and capacity to provide a measure of congestion [41]. A Roadway Congestion Index exceeding 1.0 denotes an average congestion level that is undesirable during the peak period. Black [42] uses principal component analysis to examine the relationships among multiple performance measures, including Vehicle Miles Traveled (VMT), travel time, mobility, crashes, fuel consumption, and emissions. The results indicate that VMT is the single most important factor in the context of sustainability. High VMT values do not necessarily mean high congestion; therefore, similar to the Roadway Congestion Index, VMT needs to be used in conjunction with the corresponding capacity. Thus, VMT per lane mile is a desirable performance measure. In addition, transit passenger miles and the number of intersections per capita can be important performance measures depending on the geographic location. Thus, both the demand and supply side should be taken into account for the selection of performance measure.

The Transportation Service Index (TSI) is a performance measure that seeks to quantify the movement of passenger and freight by the for-hire transportation sector [43]. This index, which is reported every month, can be used in conjunction with economic indicators to analyze the relationships between the economy and the transportation sector. Another interesting performance measure is the amount of personal money spent on transportation; this includes motor vehicles and parts, gasoline, and such transportation services as transit. The public investment on infrastructure is another important performance measure. Depending on the available data, some or all of the above performance measures can be used to develop the Transportation System PI (TSPI). The proposed modeling framework is modular and very flexible to enable the seamlessly incorporation of additional performance measures.

2.2. The Activity System. Previous studies have described the activity system as the combination of social, economic, political, and other transactions taking place over time and space $[44,45]$. These transactions create and determine the demand for transportation. For example, changes in such economic policies as gas taxes or VMT fees create changes in the demand for transportation. In this research, the activity system consists of the social, cultural, healthrelated, and economic/financial aspects. A commonly used indicator for the socio-economic development of any country is its Gross Domestic Product. However, the United Nations Development Program (UNDP) [46] recommends using the Human Development Index because it incorporates all the basic and necessary dimensions for economic prosperity. This index measures the average achievements in a country by considering (i) a long and healthy life, or life expectancy; (ii) access to knowledge, or the education index; and (iii) a generous standard of living, measured by gross national 
income per capita. Life expectancy is the average number of years a child is expected to live, assuming that the mortality rate will remain constant [46]. The Education index includes the average number of years of education received in a lifetime and the expected number of years a child will attend school, assuming constant enrollment rates. The gross national income combines the gross domestic product of a country with its income received from other countries, less similar payments made to other countries. Some of these indices or indicators are used in this study to develop the Activity System PI (ASPI).

2.3. The Environmental System. The environmental system includes the air, water, soil, and all other natural resources as well as all living organisms that are affected and/or used by the transportation and activity systems. In the United States, data from the Federal Highway Administration and the Environmental Protection Agency suggests that emissions from the transportation system has been reduced drastically over the last 30 years, despite substantial gains in VMT, gross domestic product, population, and employment [47]. This has been attributed to the introduction of the Clean Air Act in 1973 and the emergence of fuel-efficient vehicles. However, such other sectors as industrial and chemical have generated increased carbon dioxide emissions over the years, thereby affecting climate change.

The Environmental Sustainability Index (ESI) was created by the end of the 1990s by Yale and Columbia Universities [48]. This index, which is a single indicator that provides insight into human health and the environment, was promoted by the World Economic Forum. This index currently is considered the most powerful tool available to measure environmental sustainability. The ESI uses 76 variables, including air pollution, emissions related to human health, environmental factors, water pollution, and resource minimization. In addition, it incorporates response factors relating to international agreements, such as the preservation of extinct species, limitations to the use of natural resources, limitations to the release of pollutants, and biodiversity conservation.

In 2006, the ESI became the Environmental Performance Index (EPI). Since then, the EPI has been published every two years. The primary constituents of the EPI are environmental health and ecosystem vitality. Policy weights used to calculate the EPI are approximate percentages that can be summarized as follows: environmental burden of disease, $25 \%$; climate change, $25 \%$; air pollution, $17 \%$; water pollution, $17 \%$; biodiversity and habitat, $4 \%$; forestry, $4 \%$; fisheries, $4 \%$; and agriculture, $4 \%$.

\section{Methodology}

This section provides a detailed framework of the modeling approach used in this study.

The concept of Fuzzy Logic was introduced by Lotfi Zadeh in 1965. It is a way of processing data by allowing partial set membership rather than crisp set membership or non-membership $[49,50]$. Fuzzy logic provides a simple and efficient way to arrive at a definite conclusion based upon vague, ambiguous, imprecise, noisy, or missing input information. In the current study, multiple performance measures are combined and corresponding PIs are computed using fuzzy logic for the Transportation, Activity, and Environmental Systems. The PIs are calculated independently for each of the three systems. Their interdependencies are inherent in the data and are illustrated later in the results and discussion section. Considering a vector of performance measures $X$ for system $J$ as the inputs, the following three steps are used to calculate the corresponding PI: (1) an inference step (2), an aggregation step, and (3) a defuzzification step.

3.1. Inference Step. The inference step uses "if-then" rules and associated membership functions to develop and capture logical relationships between the different performance measures (inputs) and the PI (output).

3.1.1. If-then Rules. "If-then" rules are logical statements developed based on observation and expert knowledge of the system. The "if" part, left-hand side (LHS) or antecedent, is used with the inputs. The "then" part, the right-hand side (RHS) or consequent, is related to the output. An example of an "If-then" rule is as follows.

If [the VMT per lane mile is High and the TSI is Medium and the personal spending on transportation is Low], then [the TSPI is High].

As illustrated in this rule, in order to build the logical relationships between inputs and output, both the LHS and RHS are related to three fuzzy sets, High $(\mathrm{H})$, Medium $(\mathrm{M})$, and Low (L). Table 1 shows the set of "if-then" rules used in this study to calculate the TSPI. Here, three performance measures are used, namely. (i) the VMT per lane mile $(v)$, (ii) the TSI, and (iii) the personal spending on transportation ( $p s)$ per year. If required, and if the relevant data is available, additional performance measures can be used; the corresponding rules are added to the table. Similar rules have been developed for each of the PIs in order to cover all possible relationships between the chosen system performance measures and the corresponding PI. Thus, the Transportation and Activity Systems each have three inputs and 27 rules while the environmental system has four inputs and 81 rules.

3.1.2. Membership Functions. The quantitative estimation of a PI requires knowledge about the interdependencies between the system performance measures and the corresponding PI. Considering the complexity of the Transportation, Activity, and Environmental Systems, this required knowledge is limited, vague, and sometimes ambiguous. Fuzzy logic provides a mathematical construct to combine all the available knowledge and develop meaningful PI estimates. The "ifthen" rules are used in conjunction with sets of membership functions to relate the performance measures to the PIs, based on the available knowledge and data. Membership functions are used to define the grade or degree associated with every input and output. In this study, three membership functions are associated with each input and output, as illustrated in 


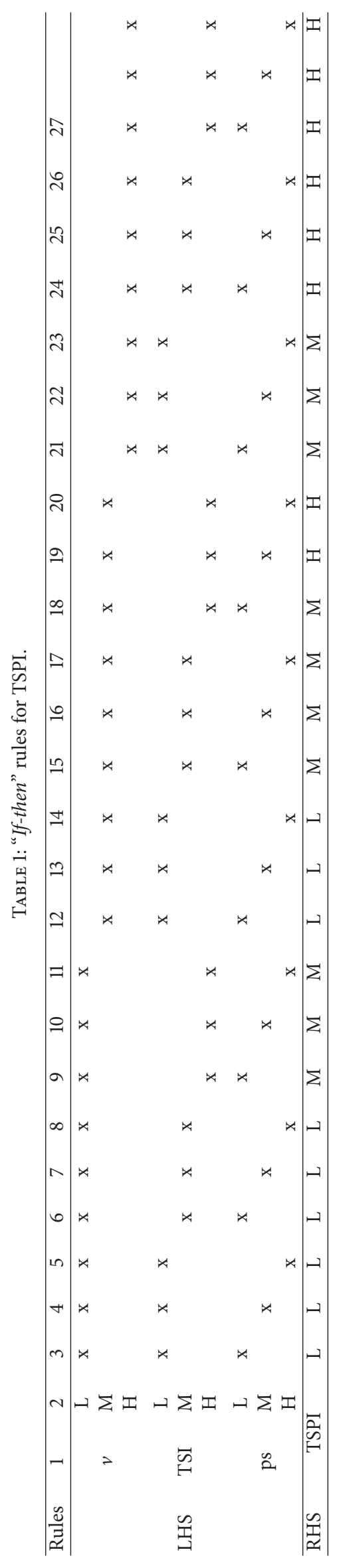


Figure 1. Triangular membership functions are used in this study because they are easy to define; only three parameters are required: a modal point, the upper width, and the lower width. In addition, due to their conceptual and computation simplicity, triangular fuzzy numbers are commonly used in practical applications $[30,51,52]$. The domain for the membership functions corresponding to the LHS is defined based on the absolute value of the associated performance measures; the domains for the PIs corresponding to the RHS are normalized so as to use a simple $[0,1]$ range. Figure 1 shows the membership functions for the calculation of the TSPI. Similar functions are defined for the other two PIs.

Once the "if-then" rules and the membership functions are defined, the Mamdani max-min composition operator and the Mamdani min implication operator are used for the fuzzy inference step [50]. For example, the three inputs for the calculation of TSPI, $v$, TSI, and ps are matched against the membership functions by using the "if-then" rules to determine the degree of activation. The degree at which each rule $\alpha$ is activated $\left(\delta^{\alpha}\right)$ is obtained by using $v$, TSI, and ps as well as the max-min operator, as shown by (1)

$$
\delta^{\alpha}=\max _{z \in Z} \min \left(\mu_{v}^{\alpha}(z), \mu_{\mathrm{TSI}}^{\alpha}(z), \mu_{\mathrm{ps}}^{\alpha}(z)\right),
$$

where $Z$ represents the universe of domains of the fuzzy sets $v$, TSI, and ps; and $\mu$ is a membership function. Equation (2) represents the membership functions of the fuzzy outcomes for the TSPI obtained, using the min implication operator

$$
\mu_{\mathrm{TSPI}^{\alpha^{*}}}=\min \left(\delta^{\alpha}, \mu_{\mathrm{TSPI}^{\alpha}}\right) .
$$

3.2. Aggregation Step. The Aggregation Step represents the aggregation of all the fuzzy output sets obtained after matching all the inputs to the membership functions by using all the "if-then" rules. A total of $R$ rules for the calculation of TSPI are defined. The aggregation step is given by (3):

$$
\mu_{\mathrm{TSPI}^{*}}=\sum_{\alpha=1}^{R} \mu_{\mathrm{TSPI}^{\alpha^{*}}} .
$$

3.3. Defuzzification Step. The output from the Aggregation Step combines all the available information by using all the defined rules. However, this output needs to be defuzzified to obtain a single crisp value for the corresponding PI, in this case, TSPI. The Center of Gravity method [50], illustrated in (4), is used for the Defuzzification Step:

$$
\mathrm{TSPI}=\frac{\sum_{\alpha=1}^{R} \bar{\theta}^{\alpha} \cdot S\left(\mu_{\mathrm{TSPI}^{\alpha^{*}}}\right)}{\sum_{\alpha=1}^{R} S\left(\mu_{\mathrm{TSPI}^{\alpha^{*}}}\right)},
$$

where $\bar{\theta}^{\alpha}$ is the centroid of the fuzzy set for the TSPI, given by the RHS of rule $\alpha$; and $S(\cdot)$ calculates the area of the membership function for a fuzzy set.

\section{Study Region and Data}

Sustainability considerations make it difficult to isolate systems and narrow the analysis to a particular transportation system or region. It is clear that impacts on the Environmental System, the Activity System, and even the Transportation System extend across regions and boundaries. In addition, the level of resolution of the available data may limit localized analyses. Hence, to illustrate the proposed method, without loss of generality, the United States is used as the study area. Similar analyses can be conducted for other regions and, ideally, the entire globe. In this case, the analysis was conducted for a period of 20 years between 1990 and 2010.

The three performance measures used in the examples in Section 3 for the estimation of the TSPI in this study were obtained from the Bureau of Transportation Statistics [43]. The ASPI includes the following performance measures provided by the United Nations [46]:

(i) Gross national income (gni);

(ii) The Education Index (ei);

(iii) Life expectancy (le).

The Environmental System Performance Index (ESPI) is based on the following performance measures:

(i) Carbon dioxide emissions (ce) [53];

(ii) Air pollutants (ap) [54];

(iii) Water pollutants $(w p)$ [55];

(iv) Energy consumption (ec) [56].

\section{Results and Discussion}

Figure 2 shows the normalized performance measures and performance index for the Transportation System. The historic trend for the VMT per lane mile (in thousands) covers a period from 1990 to 2008. It is clear that the trend is increasing except between 1990 and 1991. This could be attributed to the recession during each of those time periods [57, 58]. During 2005-2006, the VMT started decreasing probably as a consequence of the rising oil prices [59]. The trend for the TSI covers from 1990 to 2010. The base year for TSI $=100$ is taken as the year 2000. The figure shows the decrease in TSI between the years 2000 and 2002, when the terrorist attack on September 11 occurred. In 2001, there was less freight and passenger travel. Between years 2008 and 2010, the financial crisis resulted in a severe recession with consequences on TSI, as illustrated in Figure 2. Personal spending on transportation is included during 1995-2010. It is evident that spending increases from 1995-2005 as a result of economic development. However, in 2006, spending started decreasing as a result of a rise in gas prices, which hit $\$ 4$ a gallon. Later, the financial crisis during 2007-2010 resulted in decreased spending for transportation-related activities.

Figure 2 also shows the historic trend of the Transportation System performance index from 1990 to 2009. The crisp value in the $y$-axis is obtained by using the fuzzy approach discussed in earlier sections. Here, the closer the TSPI to 1, the better the performance of the Transportation System; if its value is close to 0 , then performance is poor. The crisp values can only be used as a relative measure to compare between alternatives and scenarios. It cannot be used to assess 


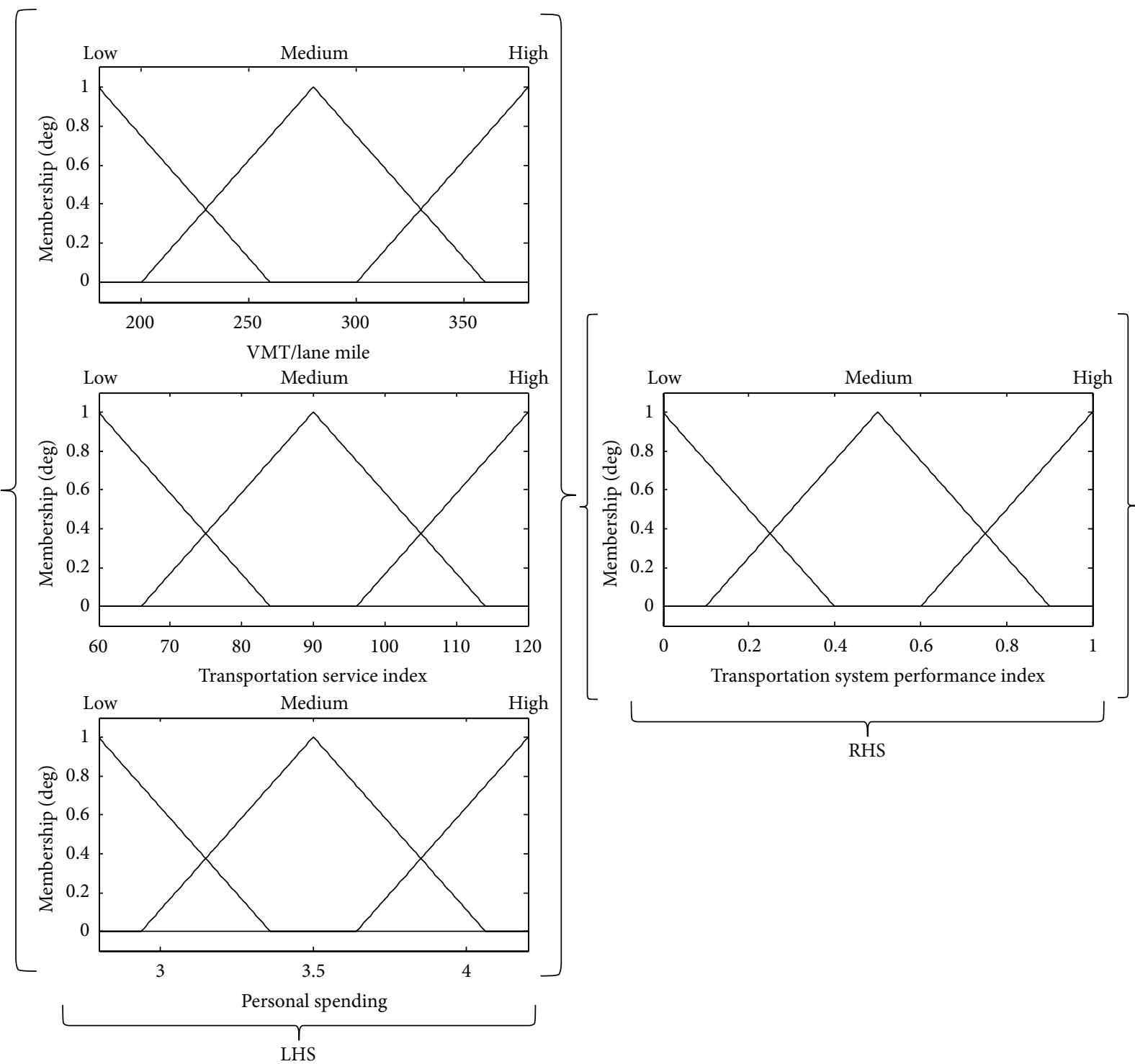

Figure 1: Membership functions for the calculation of the Transportation System Performance Index.

the absolute value of the sustainability of the system. It is evident that TSPI has the best value between years 2005 and 2006, when the economy was booming, and the least value between years 1990 and 1991. The curve for the TSPI follows a pattern consistent with VMT/lane mile and TSI. That is, the TSPI increases with the increase in VMT/lane mile and TSI. According to Genier [59], rising oil prices during 2005-2006 has led to reduced VMT and promoted alternate modes of transportation, such as transit and car-pooling, as well as the use of more efficient vehicles.

Figure 3 shows the normalized performance measures and performance index for the Activity System. The trend of the average annual income in Gross National Income per capita is provided from 1990 to 2010 . The trend increased, with a high growth rate until 1999. The rate started decreasing in 2000 following the technology bust, also known as the DotCom Bubble, and later in 2006, following the housing crisis.
It is noted that the rate of growth in income is less in the past decade as compared to earlier decades.

The trend of the average annual education index is provided from 1990 to 2010 . This index started increasing from 1990 to 2000, the primary reason being the invention of new technologies and innovations that kept the United States in the forefront of education. In addition, a new wave of technological revolution was seen in the form of startups. Also, science, engineering, and medical disciplines saw a new era of growth and development. The reason for a slight decline in the education index between 2000 and 2004 is not clear yet. The trend of the average annual life expectancy is provided from 1990 to 2010. The average life expectancy has increased from 74 years in 1990 to 80 years in 2010. This increase can be attributed to the technological advancement in medical facilities and billions of dollars spent on research and the development of new and effective drugs. 


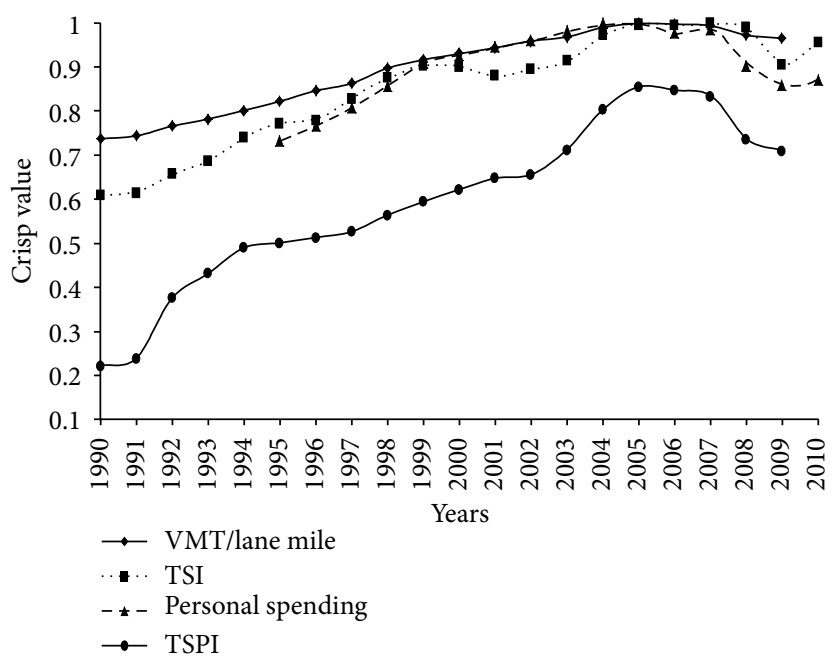

Figure 2: Historical Trend of Transportation System Performance Index and its Performance Measures.

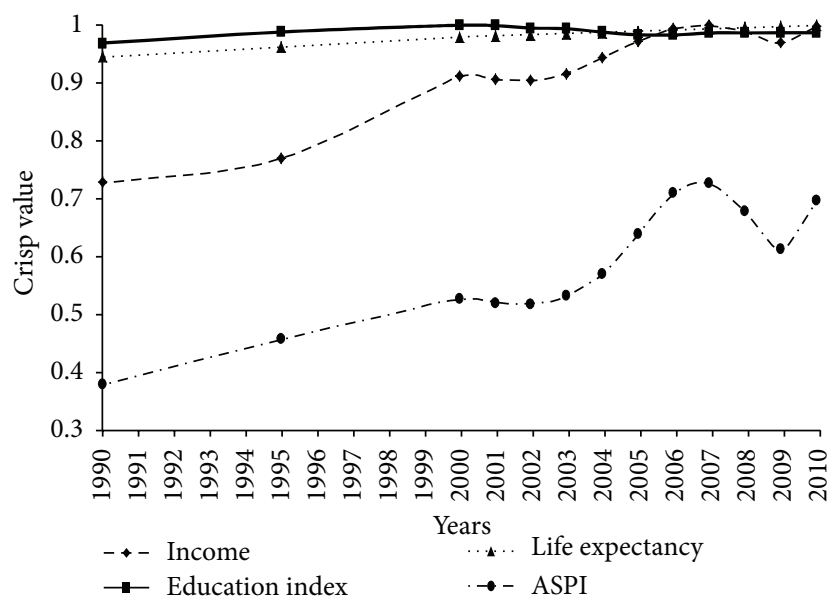

Figure 3: Historical Trend of Activity System Performance Index and its Performance Measures.

Figure 3 also shows the trend for the Activity System's performance index from 1990 to 2010. This index started increasing from year 1990 until the year 2000 as a result of economic development. Starting with the technology bust in 2000 and terrorist attacks in 2001, the economic activity started to decrease and did not recover until the end of the year in 2003. Since 2003, the Activity System started an upward trend before hitting a peak in 2007. The financial crisis from 2007 to 2009 resulted in a dramatic decrease in economic activity, often compared as equivalent to the Great Depression of 1930s. The year 2009 marks the period of "official recovery" from the recession.

Figure 4 shows the normalized performance measures and performance index for the Environmental System. The trend of carbon dioxide emissions is provided from years 1990 to 2008. This is an increasing trend except during 1990-1991,

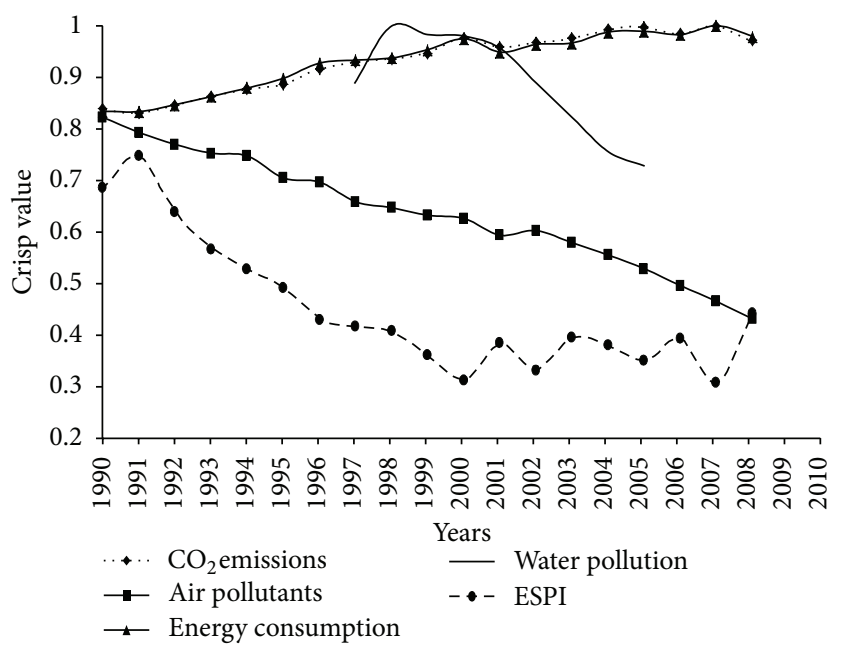

Figure 4: Historical Trend of Environmental System Performance Index and its Performance Measures.

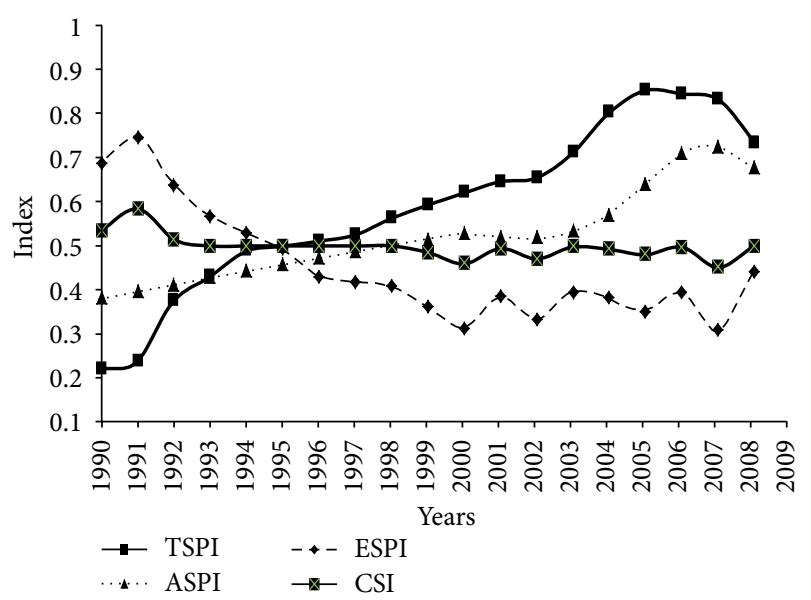

Figure 5: Historical Trend of Performance Indices and the Composite Sustainability Index for the Transportation, Activity, and Environmental systems.

a time of global political unrest and high inflation; 20002002, due to the technology bust and September 11 attacks; 2005-2006, due to high gas prices; and 2007-2008, with the financial crisis. The trend of air pollutants is provided from 1990 to 2008. With the introduction of the Clean Air Act in 1973 , there has been a dramatic reduction in air pollution. In addition, the introduction of innovative technologies, such as hybrid and battery powered vehicles, have led to reduced air pollution over the years.

The trend for water pollutants is provided from 1997 to 2005. This trend decreases with time as a result of innovative and efficient waste management techniques. The trend for the average annual energy consumption in quadrillion British Thermal Units is provided from 1990 to 2008. This trend indicates that energy consumption decreased during the financial crisis of 1990-1991. After 1991, energy consumption started an upward trend and finally peaked in 2007. However, there were short periods of decline in energy consumption 


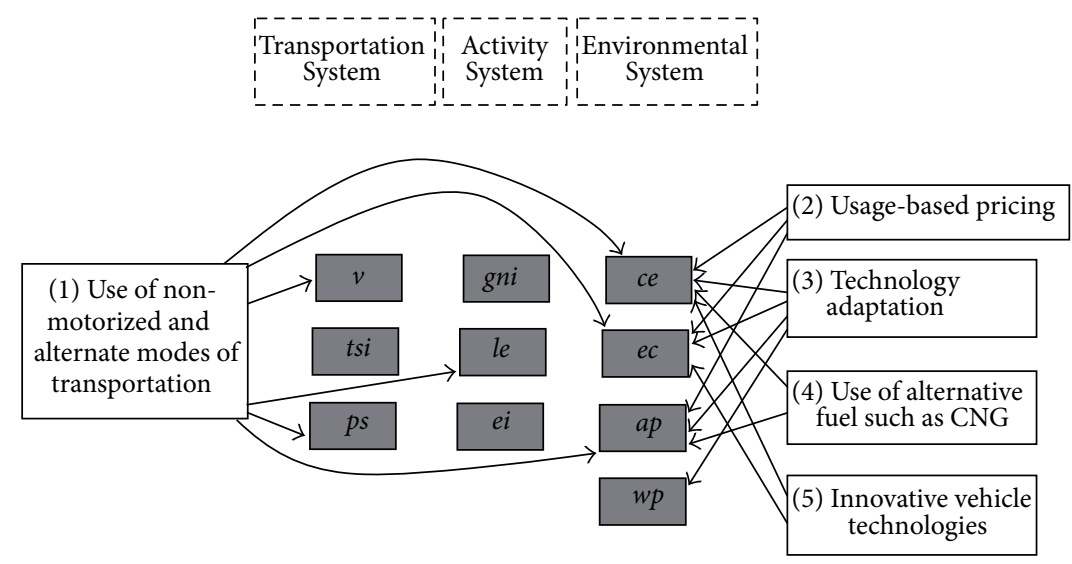

FIgURE 6: Direct effects of policy options on Performance Measures.

both in 2001, attributed to the September 11 terrorist attacks, and 2006, due to high oil prices. The terrorist attack resulted in decreased travel and less economic activity, while the exorbitant high oil prices promoted the use of new batterypowered and hybrid vehicle technologies.

Figure 4 also shows the trend of the Environmental System's performance index from 1990 to 2008. If the value for ESPI is close to 1, then the environmental system is excellent; if its value is close to 0 , then the system quality is very poor. The best value for ESPI occurred during 1990-1995, when economic development was slow as a result of global political unrest and the first gulf war. Since 2000, the quality started to improve, probably as a consequence of multiple periods of economic contractions. Again, the year 2007 marked the beginning of a slight uptrend in the index as a result of a global financial crisis. In general, the environment improves during periods when economic activity is down and/or oil prices are high. In addition, the curve for the ESPI follows a pattern consistent with carbon-dioxide emissions and energy consumption. That is, the ESPI decreases with the increase in carbon-dioxide emissions and energy consumption.

Figure 5 shows the three performance indices from 1990 to 2009. In this figure the Transportation and Activity Systems follow an increasing trend over the years, with similar periods of growth and contractions; on the other hand, the Environmental System follows a reverse pattern. These trends seem intuitive, as growth in the economy and the transportation sectors are expected to happen simultaneously; this growth requires resources from the environment, thereby increasing emissions and energy consumption.

Figure 5 also illustrates a Composite Sustainability Index (CSI), an index used to access the overall sustainability of the SOS used this research. It is calculated using the proposed fuzzy logic approach and the performance index for the Transportation, Activity, and Environmental Systems. The CSI shows an overall increasing trend from year 1990 to 1995. However, considering the overall negative slope and corresponding decrease on the ESPI, the CSI does not continue increasing after 1995 presenting some negative periods and increases only when there is a significant improvement on the ESPI. Based on these observations and the chosen performance measures, negative impacts to the environment seem to be associated with negative consequences on the overall sustainability of the SOS. In general, under the proposed framework, a system is sustainable if the slope of the corresponding PI curve presents a nonnegative slope. Similarly, the overall SOS is sustainable if the slope of the CSI is nonnegative. The axioms presented in this paper are an attempt to summarize our observations based on chosen performance measures. There is a vast literature with similar observations. For example, Young et al. [60] as well as Lahiri and Yao [61] have observed that the transportation and activity system follows a lead-lag phase pattern and environment system is inversely related to the other two. The following axioms can be postulated to assess the sustainability or the unsustainability of our SOS.

(1) The SOS is sustainable when the overall slopes for the TSPI, ASPI, and ESPI have a positive trend. This is an ideal scenario with positive growth in all systems, and implies that there is no need of nonrenewable natural resources to sustain growth in the transportation and the economy.

(2) The SOS is unsustainable when the slopes of TSPI and ASPI have a positive trend but the slope of ESPI has a negative trend. This is the scenario that we have been observing in the USA. In general, the SOS is unsustainable when the overall trend of at least one of the three slopes is negative.

(3) The SOS is sustainable when the overall slopes for the TSPI, ASPI, and ESPI have a nonnegative trend. This scenario is sustainable because all the transportation and other social activities can continue in perpetuity without degradation of the environmental system. Although this is a scenario preferred over an unsustainable situation, it may represent an unstable equilibrium that can easily become unsustainable. 


\section{Policy Perspectives}

This section discusses some policy options for the sustainability of the SOS studied in this research. Some of these options have been implemented in the past revealing some of their effects. Other options are currently under consideration by multiple stakeholders. Figure 6 illustrates five policy options that can be used to improve performance and support the sustainability of the SOS considered here. The dashed boxes correspond to the three major systems, the grey boxes represent the performance measures within each system, and the suggested policies are depicted by rectangular boxes. These policies have direct and indirect effects on some performance measures and systems. Only the direct effects of the proposed policies are shown through the arrows in Figure 6. Conclusion regarding indirect effects will be immature at this point; hence are not discussed here. Each policy is described as follows.

Use of Nonmotorized and Alternate Modes of Transportation. This policy consists of the promotion of non-motorized modes of transportation, such as bicycles, and the use of alternatives for driving alone, such as transit and carpooling. The success of this policy depends on multiple factors, including land use. It may require the establishment of commuter-friendly and transit-friendly development near the central business district. In addition, changes in travel and demand patterns depend on the users' preferences and attitudes as well as convenience. Expected consequences of implementing this policy, among others, include reductions on (i) VMT [62, 63], (ii) air pollution, (iii) carbon dioxide emissions, (iv) energy consumption, (v) health issues, and (vi) out-of-pocket cost. The money and resources saved can be used to improve such sectors as education and research with further impacts on the gross domestic product.

Usage Based Pricing. Currently, the implementation of a VMT fee is being considered as a viable alternative to replace the current fuel tax for collecting the required resources for highway maintenance [64]. This policy also can promote the reduction of VMT, along with all the other associated consequences. However, this policy faces a number of deployment as well as acceptance issues.

Technology Adaptation. The rapid industrialization and technological revolution has resulted in reduced emissions over the years. For example, the use of efficient boilers in coal-fired plants will help reduce carbon dioxide emissions, pollution, and energy consumption $[65,66]$. Health related issues will be reduced as a consequence of less pollution.

Use of Alternative Fuels Such As Compressed Natural Gas (CNG). The use of alternative fuels in the form of CNG will reduce carbon-dioxide emissions and pollution $[67,68]$. This will lead to a green and cleaner environment [69] with all the associated benefits to health, the economy, and the quality of life. In the United States, the reserves of natural gas are larger than those of petroleum [70]. Hence, this policy seems plausible from an environmental and economic perspective. The only drawbacks are the time and cost associated with retrofitting vehicles and the supply chain.

Innovative Vehicle Technologies. Replacement of conventionally powered vehicles with hybrid and electric vehicles will reduce carbon-dioxide emissions and nonrenewable fuel consumption [71]. Automakers are particularly interested in this policy [72]. In addition, the federal government provides tax incentives to develop and manufacture lithium ion batteries in the United States.

Ideally, each of these policies is evaluated before deployment and adoption. Some of them are currently under analysis by multiple agencies and sectors. The proposed framework in this study is descriptive rather than normative. Hence, it can only be used to appreciate the effectiveness and benefits of past policies. Currently, the proposed framework is been extended to enable a normative analysis in order to evaluate potential policy alternatives such as those described earlier.

\section{Conclusions}

Previous studies about sustainable transportation have either focused only on the transportation system, or have not used a methodology that enables the treatment of incomplete, vague, and qualitative information present in the problem context. This study adopted a holistic approach to compute Performance Indices for a SOS including the Transportation, Activity, and Environmental systems. The Performance Indices are synthetized to calculate a Composite Sustainability Index to evaluate the sustainability of the overall SOS. Considering the complexity, vagueness, nonlinearity, qualitative, and incomplete information characterizing the quantification of the Performance and Composite Sustainability Indices, a fuzzy logic approach was used to calculate these indices. Historic events and policy changes indicated that fuzzy logic provided an adequate approach to estimate both the Performance Indices and the Composite Sustainability Index.

Results of the analysis for the US showed that the Transportation and Activity Systems both follow a positive trend over the years, with similar periods of growth and contractions. In contrast, the environmental system follows a reverse pattern. This seems intuitive, as periods of economic and transportation growth is expected to have a negative effect on the environment, leading to increased emissions and energy consumption. In general, the performance of the environmental system has decreased significantly over time. Policies adopted to protect the system have shown positive effects. However, the current performance of the Environmental System is questionable, and long-term policies need to be developed.

The conclusions provided here are based on the results obtained using a limited number of performance measures. Adding or removing performance measures are expected to change the results and conclusions. In general, following a holistic approach, it is expected that the more relevant performance measures are used, the more comprehensive 
and accurate the analysis is. Planning and operational policies for the sustainability of the Transportation, Activity, and Environmental systems can be developed using the proposed approach. Considering the current practice of making planning decisions at the regional and jurisdictional level, the framework used in this study is currently been extended to enable the analysis of regional systems including large metropolitan areas. A simulation-based approach has been developed to estimate multiple performance measures required to calculate adequate performance indices.

\section{References}

[1] EIA (Energy Information Administration), International Energy Outlook, EIA, Washington, DC, USA, 2006.

[2] J. J. MacKenzie, "Alternative fuels to reduce petroleum consumption, global warming gases, and urban air pollution," in Symposium on Challenges and Opportunities for Global Transportation in the 21st Century, John A. Volpe Transportation Systems Center, Cambridge, Mass, USA, 1995.

[3] J. Zheng, C. Atkinson-Palombo, C. McCahill, R. O’Hara, and N. W. Garrick, "Quantifying the economic domain of transportation sustainability," in Proceedings of the Annual Meeting of the Transportation Research Board-CDROM, Washington, DC, USA, 2011.

[4] S. Bell and S. Morse, Sustainability Indicators: Measuring the Immeasurable, Earthscan, London, UK, 2nd edition, 2008.

[5] J. R. E. Harger and F. M. Meyer, "Definition of indicators for environmentally sustainable development," Chemosphere, vol. 33, no. 9, pp. 1749-1775, 1996.

[6] H. Bossel, "Assessing viability and sustainability: a systemsbased approach for deriving comprehensive indicator sets," Conservation Ecology, vol. 5, no. 2, article 12, 2001.

[7] C. M. Jeon, A. A. Amekudzi, and R. L. Guensler, "Evaluating plan alternatives for transportation system sustainability: Atlanta metropolitan region," International Journal of Sustainable Transportation, vol. 4, no. 4, pp. 227-247, 2010.

[8] T. Litman, "Developing indicators for comprehensive and sustainable transport planning," Transportation Research Record, no. 2017, pp. 10-15, 2007.

[9] J. A. Paravantis and D. A. Georgakellos, "Trends in energy consumption and carbon dioxide emissions of passenger cars and buses," Technological Forecasting and Social Change, vol. 74, no. 5, pp. 682-707, 2007.

[10] S. Huzayyin and H. Salem, "Analysis of thirty years evolution of urban growth, transport demand and supply, energy consumption, greenhouse and pollutants emissions in Greater Cairo," Research in Transportation Economics, vol. 40, no. 1, pp. 104-115, 2013.

[11] T. Litman, Climate Change Emission Valuation for Transportation Economic Analysis, Victoria Transport Policy Institute, 2012.

[12] E. J. Zolnik, "Estimates of statewide and nationwide carbon dioxide emission reductions and their costs from cash for clunkers," Journal of Transport Geography, vol. 24, pp. 271-281, 2012.

[13] G. R. Conway, "Sustainability in agricultural development: trade-offs with productivity, stability and equitability," Journal of Farming Systems Research and Extension, vol. 4, no. 2, pp. 1$14,1994$.
[14] R. Gray, "Economic measures of sustainability," Canadian Journal of Agricultural Economics, vol. 39, no. 4, pp. 627-635, 1991.

[15] WCED (World Commission on Environment and Development), Our Common Future, Oxford University Press, Oxford, UK, 1987.

[16] R. Costanza, B. Norton, and B. D. Haskell, Ecosystem Health: New Goals for Environmental Management, Island Press, Washington, DC, USA, 1992.

[17] IUCN (World Conservation Union), UNEP (United Nations Environment Programme), and WWF (World Wide Fund for Nature), Caring for the Earth: A Strategy for Sustainable Living, IUCN, Gland, Switzerland, 1991.

[18] K. Rennings and H. Wiggering, "Steps towards indicators of sustainable development: linking economic and ecological concepts," Ecological Economics, vol. 20, no. 1, pp. 25-36, 1997.

[19] G. Munda, Fuzzy Information on Multi-Criteria Environmental Models, Physika, Heidelberg, Germany, 1995.

[20] J. Zietsman, L. R. Rilett, and S. J. Kim, “Transportation corridor decision-making with multi-attribute utility theory," International Journal of Management and Decision Making, vol. 7, no. 2-3, pp. 254-266, 2006.

[21] R. Islam and T. L. Saaty, "The analytic hierarchy process in the transportation sector," in Multiple Criteria Decision Making for Sustainable Energy and Transportation Systems, vol. 634 of Lecture Notes in Economics and Mathematical Systems, Springer, Physica, Berlin, Heidelberg, 2010.

[22] G. A. Mendoza and R. Prabhu, "Multiple criteria decision making approaches to assessing forest sustainability using criteria and indicators: a case study," Forest Ecology and Management, vol. 131, no. 1-3, pp. 107-126, 2000.

[23] H. J. Zimmermann, Fuzzy Set Theory and Its Applications, Kluwer Academic, Boston, Mass, USA, 4th edition, 2001.

[24] S. Yedla and R. M. Shrestha, "Multi-criteria approach for the selection of alternative options for environmentally sustainable transport system in Delhi," Transportation Research A, vol. 37, no. 8, pp. 717-729, 2003.

[25] D. Tsamboulas and G. Mikroudis, "EFECT_evaluation framework of environmental impacts and costs of transport initiatives," Transportation Research D, vol. 5, no. 4, pp. 283-303, 2000.

[26] A. Awasthi and H. Omrani, "A hybrid approach based on AHP and belief theory for evaluating sustainable transportation solutions," International Journal of Global Environmental Issues, vol. 9, no. 3, pp. 212-226, 2009.

[27] T. L. Saaty, The Analytic Hierarchy Process, McGraw-Hill, New York, NY, USA, 1980.

[28] G. Crawford and C. Williams, "A note on the analysis of subjective judgment matrices," Journal of Mathematical Psychology, vol. 29, no. 4, pp. 387-405, 1985.

[29] J. Barzilai, "Consistency measures for pairwise comparison matrices," Journal of Multi-Criteria Decision Analysis, vol. 7, no. 3, pp. 123-132, 1998.

[30] G. J. Klir and B. Yuan, Fuzzy Sets and Logic: Theory and Application, Prentice Hall, Upper Saddle River, NJ, USA, 1995.

[31] R. R. Yager, "Aggregation operators and fuzzy systems modeling," Fuzzy Sets and Systems, vol. 67, no. 2, pp. 129-145, 1994.

[32] W. Silvert, "Ecological impact classification with fuzzy sets," Ecological Modelling, vol. 96, no. 1-3, pp. 1-10, 1997.

[33] A. Awasthi, S. S. Chauhan, and H. Omrani, "Application of fuzzy TOPSIS in evaluating sustainable transportation systems," 
Expert Systems with Applications, vol. 38, no. 10, pp. 1227012280, 2011.

[34] S. Opricovic and G. H. Tzeng, "Fuzzy multicriteria model for postearthquake land-use planning," Natural Hazards Review, vol. 4, no. 2, pp. 59-64, 2003.

[35] G. A. Mendoza and R. Prabhu, "Fuzzy methods for assessing criteria and indicators of sustainable forest management," Ecological Indicators, vol. 3, no. 4, pp. 227-236, 2004.

[36] K. F. R. Liu, "Evaluating environmental sustainability: an integration of multiple-criteria decision-making and fuzzy logic," Environmental Management, vol. 39, no. 5, pp. 721-736, 2007.

[37] T. Prato, "A fuzzy logic approach for evaluating ecosystem sustainability," Ecological Modelling, vol. 187, no. 2-3, pp. 361368, 2005.

[38] L. A. Marks, E. G. Dunn, J. M. Keller, and L. D. Godsey, "Multiple criteria decision making (MCDM) using fuzzy logic: an innovative approach to sustainable agriculture," in Proceedings of the 3rd International Symposium on Uncertainty Modeling and Analysis and Annual Conference of the North American Fuzzy Information Processing Society (ISUMA-NAFIPS'95), pp. 503-508, IEEE Computer Society, Washington, DC, USA, September 1995.

[39] R. L. Ackoff, “Towards a system of systems concepts," Management Science, vol. 17, no. 11, pp. 661-671, 1971.

[40] T. Lomax, S. Turner, and G. Shunk, Quantifying Congestion, vol. 1, National Cooperative Highway Research Program, Transportation Research Board, National Academy Press, Washington, DC, USA, 1997.

[41] D. L. Schrank and T. J. Thomas, Urban Mobility Report, Texas Transportation Institute, College Station, Tex, USA, 2009.

[42] W. R. Black, "Sustainable transport and potential mobility," European Journal of Transport and Infrastructure Research, vol. 2, no. 3-4, pp. 179-196, 2002.

[43] BTS (Bureau of Transportation Statistics), "Key Transportation Indicators," 2011, http://www.bts.gov/publications/ key_transportation_indicators.

[44] M. L. Manheim, Fundamentals of Transportation Systems Analysis, Volume 1: Basic Concepts, MIT Press, Boston, Mass, USA, 1979.

[45] E. Cascetta, Transportation Systems Analysis: Models and Applications, Springer, New York, NY, USA, 2009.

[46] UNDP (United Nations Development Programme), "Human Development Report," 2010, http://www.hdr.undp.org/en/statistics/.

[47] ARTBA (American Road and Transportation Builders Association), 2011, http://www.artba.org/mediafiles/regulatorylegalartbacafecommentsjanuary2011.pdf.

[48] ESI (Environmental Sustainability Index), Benchmarking National Environmental Stewardship, Yale Center for Environmental Law and Policy, Yale University, 2005, http:// www.yale.edu/esi/ESI2005_Main_Report.pdf.

[49] R. R. Yager, S. Ovchinnikov, R. M. Tong, and H. T. Nguyen, Fuzzy Sets and Applications: Selected Papers By L.A. Zadeh, John Wiley \& Sons, New York, NY, USA, 1987.

[50] L. H. Tsoukalas and R. E. Uhrig, Fuzzy and Neural Approaches in Engineering, John Wiley \& Sons, New York, NY, USA, 1997.

[51] W. Pedrycz, "Why triangular membership functions?" Fuzzy Sets and Systems, vol. 64, no. 1, pp. 21-30, 1994.

[52] C. H. Yeh and H. Deng, "A practical approach to fuzzy utilities comparison in fuzzy multicriteria analysis," International Journal of Approximate Reasoning, vol. 35, no. 2, pp. 179-194, 2004.
[53] EIA (Energy Information Administration), Emissions of Greenhouse Gases in the United States, Washington, DC, USA, 2009, http://www.eia.gov/environment/emissions/ghg_report/ pdf/tbl6.pdf.

[54] EPA (Environmental Protection Agency), Clearinghouse for Inventories and Emissions Factors (CHIEF), Current Emission Trends Summaries, 2009, http://www.epa.gov/ttn/ chief/trends/index.html.

[55] World Databank, World Development Indicators and Global Development Finance, 2010, http://www.databank.worldbank .org/ddp/home.do?Step=2\&id=4\&hActiveDimensionId=WDI _Series.

[56] EIA (Environmental Information Administration), Monthly Energy Review, 2011, http://www.eia.doe.gov/emeu/mer/contents.html.

[57] M. Mussa, "U.S. Macroeconomic policy and third world debt," Cato Journal, vol. 4, no. 1, 1984, http://www.cato.org/ sites/cato.org/files/serials/files/cato-journal/1984/5/cj4n1-5.pdf.

[58] R. H. Kamery, "A brief review of the recession of 1990-1991," Allied Academies International Conference, Proceedings of the Academy of Legal, Ethical and Regulatory Issues, vol. 8, no. 2, 2004.

[59] B. Genier, "Peak Demand-U.S. Gasoline Demand Likely Peaked in 2007," Cambridge Energy Research Associates (CERA), 2008, http://www2.cera.com/news/details/1,2318,956 8,00.html.

[60] P. Young, K. Notis, G. Feuerberg, and L. Nguyen, "BTS Technical Report: transportation services index and the economy," 2007.

[61] K. Lahiri and W. Yao, "A dynamic factor model of the coincident indicators for the US transportation sector," Applied Economics Letters, vol. 11, no. 10, pp. 595-600, 2004.

[62] T. Litman and R. Steele, Land Use Impacts on Transport: How Land Use Factors Affect Travel Behavior, Victoria Transport Policy Institute, 2011.

[63] Nelson/Nygaard, Crediting Low-Traffic Developments: Adjusting Site-Level Vehicle Trip Generation Using URBEMIS, Urban Emissions Model, California Air Districts, 2005.

[64] D. S. Kim, D. Porter, and R. Wurl, Technology Evaluation for Implementation of VMT Based Revenue Collection Systems, Oregon Department of Transportation, Road User Fee Task Force, Salem, Ore, USA, 2002.

[65] K. Jordal, M. Anheden, J. Yan, and L. Strömberg, "Oxyfuel Combustion for coal-fired power generation with $\mathrm{CO}_{2}$ capture-opportunities and challenges," in Proceedings of the 7th International Conference on Greenhouse Gas Control Technologies (GHGT-7), Vancouver, Canada, 2004.

[66] M. B. Toftegaard, J. Brix, P. A. Jensen, P. Glarborg, and A. D. Jensen, "Oxy-fuel combustion of solid fuels," Progress in Energy and Combustion Science, vol. 36, no. 5, pp. 581-625, 2010.

[67] M. P. Hekkert, F. H. J. F. Hendriks, A. P. C. Faaij, and M. L. Neelis, "Natural gas as an alternative to crude oil in automotive fuel chains well-to-wheel analysis and transition strategy development," Energy Policy, vol. 33, no. 5, pp. 579-594, 2005.

[68] P. Goyal and Sidhartha, "Present scenario of air quality in Delhi: a case study of CNG implementation," Atmospheric Environment, vol. 37, no. 38, pp. 5423-5431, 2003.

[69] S. Yeh, "An empirical analysis on the adoption of alternative fuel vehicles: the case of natural gas vehicles," Energy Policy, vol. 35, no. 11, pp. 5865-5875, 2007. 
[70] M. Q. Wang and H. S. Huang, "A full fuel-cycle analysis of energy and emissions impacts of transportation fuels produced from natural gas," Report No. ANL/ESD-40, Center for Transportation Research, Energy Systems Division, Argonne National Laboratory, IL, US Department of Energy, 2000.

[71] M. S. Dresselhaus and I. L. Thomas, "Alternative energy technologies," Nature, vol. 414, no. 6861, pp. 332-337, 2001.

[72] S. G. Wirasingha, N. Schofield, and A. Emadi, "Plug-in hybrid electric vehicle developments in the US: trends, barriers, and economic feasibility," in Proceedings of the IEEE Vehicle Power and Propulsion Conference (VPPC'08), Harbin, China, September 2008. 

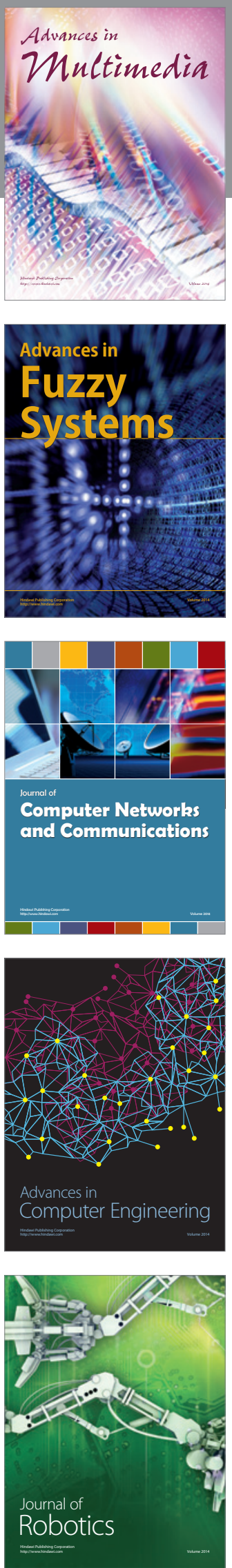

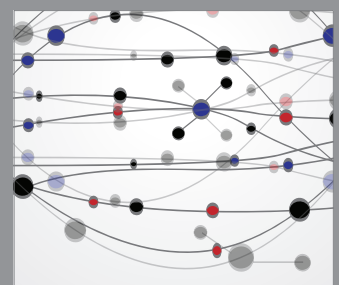

The Scientific World Journal
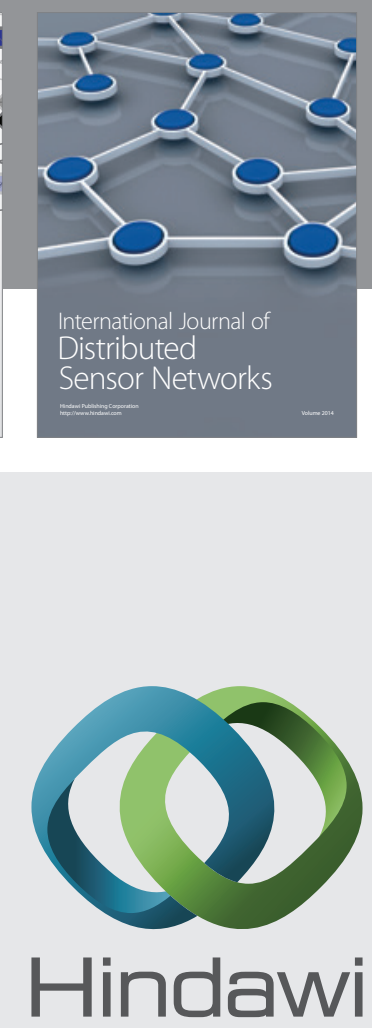

Submit your manuscripts at

http://www.hindawi.com
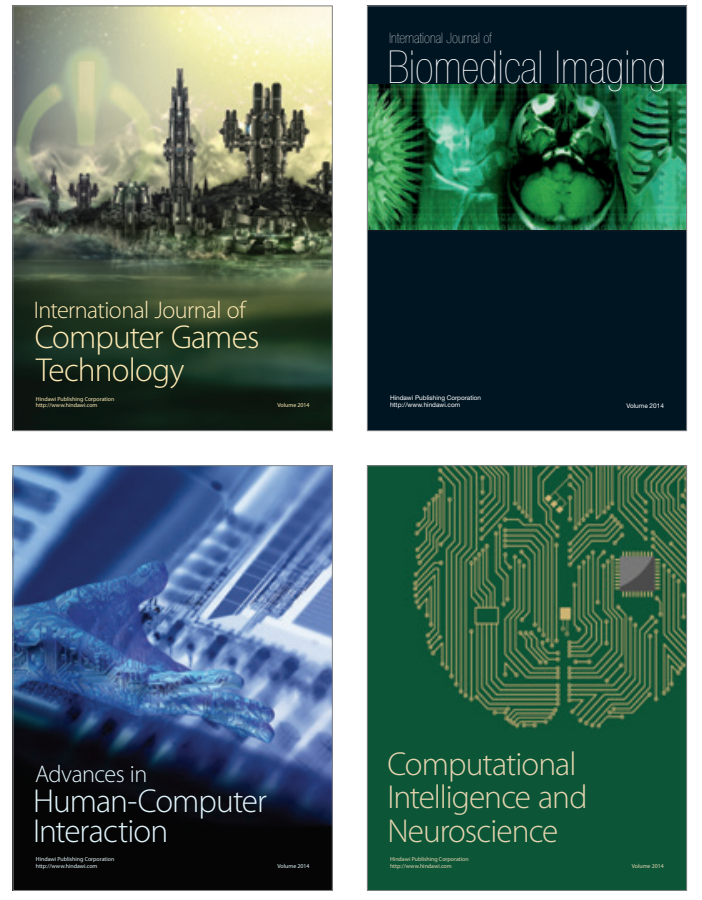
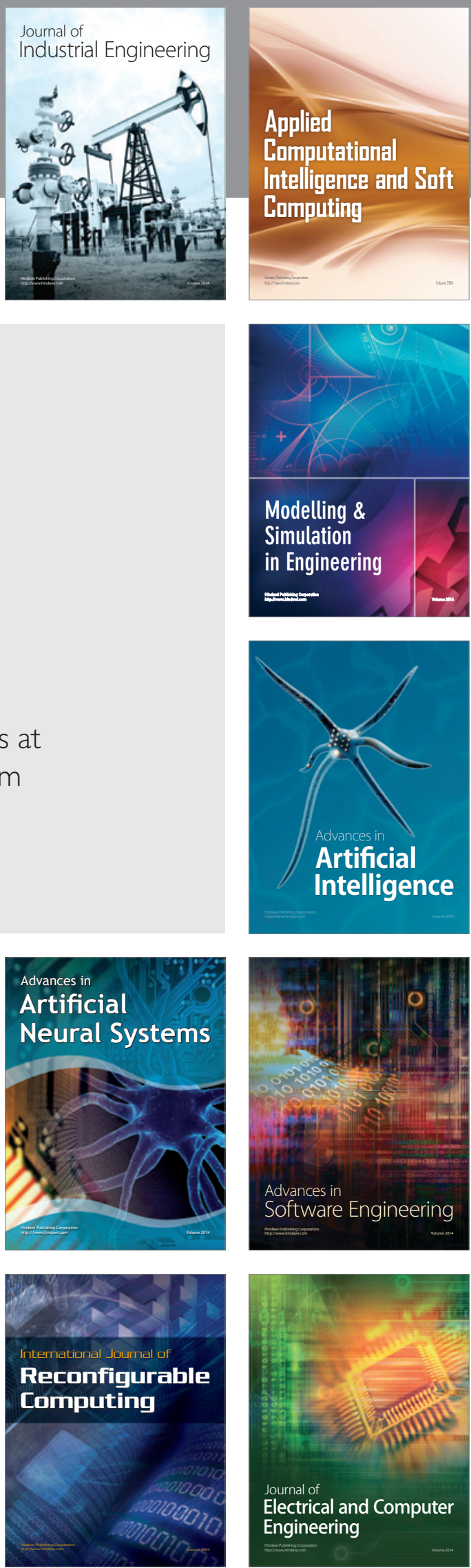